\title{
Erectile Function Before and After Non-Nerve-Sparing Retropubic Radical Prostatectomy
}

\author{
Jørgen Bjerggaard Jensen, $\mathrm{MD}^{\mathbf{1}}$, Jørgen $\mathrm{K}$. Johansen, $\mathrm{MD}^{\mathbf{1}}$ \\ ${ }^{1}$ Department of Urology, Regional Hospital of West Jutland, Denmark. \\ jb@skejby.net \\ *Corresponding Author: Jørgen Bjerggaard Jensen, MD, Department of Urology, Regional Hospital of \\ West Jutland, Denmark.
}

\section{Abstract}

Objective: To assess the degree of preoperative erectile dysfunction (ED) and postoperative erectile function (EF) following non-nerve-sparing retropubic radical prostatectomy (NNS-RRP).

Material and Methods: Between November 2004 and June 2007, 165 patients with clinically localized adenocarcinoma of the prostate underwent NNS-RRP at our department. In August 2007 all patients still alive were sent questionnaires regarding pre-and post-operative EF including the short version of International Index of Erectile Function (IIEF-5). One hundred and fifty-eight questionnaires were returned with 148 adequately filled in. Median (range) follow-up was 13 (1-33) months.

Results: Twenty-six percent of the patients had no preoperative sexual activity, mainly caused by ED. Five percent used PDE-5 inhibitors or injection therapy to achieve erection. Additional $10 \%$ had an IIEF-5 score of 21 or less suggesting mild or moderate ED. Thus only $59 \%$ of the patients had sexual activity with a normal EF preoperative. Postoperative EF was significantly better in patients with a follow-up of 12 months or more compared to patients with a shorter follow-up. Preserved EF was also more common in patients younger than 60 years and in patients with no preoperative use of PDE-5 inhibitors and/or a preoperative IIEF-5 score of 22 or more. In patients with more than 12 months of follow-up the overall percentages of preserved EF with or without use of medical aid were $45 \%$ and $16 \%$ respectively.

Conclusions: EF is preserved in some patients despite a non-nerve-sparing procedure. Many of the patients may benefit from medical aid.

Keywords: Cancer, Erectile function, Non-nerve-sparing, Prostatectomy, Retropubic, Sexual function

\section{INTRODUCTION}

Radical prostatectomy is an effective treatment of localized adenocarcinoma of the prostate [1]. Within the last decade the use of systematic and nonsystematic PSA screening has caused more patients to be diagnosed with minimal and presumable non aggressive disease. The attention has therefore shifted from surgery with an optimal cancer control to the surgical approach that causes the least possible side-effects. Thus, the nerve-sparing procedure has been suggested to preserve erectile function (EF) in patients with organ confined disease.

Whether the disease is truly organ confined can however be difficult to predict preoperatively. The nerve-sparing procedure may therefore be associated with a higher risk of cancer recurrence and ultimately a higher disease specific mortality.

It is therefore important to investigate, how many patients that would not benefit from a nerve-sparing prostatectomy due to preoperative erectile dysfunction (ED). With the present study we also wanted to investigate how many patients had preserved EF despite a non-nerve-sparing procedure.

\section{Materials And Methods}

From November 2004 trough to June 2007, 165 patients with clinically localized adenocarcinoma 
of the prostate underwent non-nerve-sparing radical retropubic prostatectomy (NNS-RRP) at our department. In August 2007, 163 patients still alive were sent questionnaires of pre- and post-operative EF including the short version of International Index of Erectile Function (IIEF-5) [2]. The additional questions complementing the IIEF-5 are shown in Appendix 1.

Patients with an IIEF-5 score of 22-25 were considered to have normal EF according to Rosen [2], while an IIEF-5 score of 21 or less were considered to be associated with some degree of ED.

Receiver operating characteristics (ROC) curves [3] were applied to estimate the optimal minimum of follow-up before EF could be considered approximately stabile. Dividing the patients into different age groups were also done based on ROC curves.

Statistical analyses were performed using the MedCalc $®$ computer software. Comparison of incidences was assessed using Fisher's exact test or Chi square test where appropriate. $\mathrm{P}$ values were based on two-sided testing at a $5 \%$ significance level.

\section{RESULTS}

After one written reminder 158 patients (97\%) had returned the questionnaire. Ten stated that they did not want to answer the questions. The remaining 148 questionnaires were returned adequately filled in.

The 148 patients had a median (range) follow-up of 13 (1-33) months ( \pm 5.3 standard deviations (SD)). Patient age was mean 62.9 years $( \pm 4.9 \mathrm{SD})$.

Preoperatively, 38 patients (26\%) had no sexual activity. This was due to severe ED in 25 patients, lack of desire in 8 patients while 5 patients had no partner. Eight patients (5\%) used PDE-5 inhibitors to achieve and/or maintain erections. Fifteen patients (10\%) who had sexual activity without medical aid had an IIEF-5 score of 21 or less suggesting mild to moderate ED. Thus, 87 patients (59\%) were sexually active with a normal EF preoperatively.

Postoperatively $10 \%$ of the patients overall had resumed normal sexual activity without using any kind of aid. Including patients who needed some kind of medical aid (PDE-5 inhibitors, intra-urethral therapy or injection therapy) a total of $32 \%$ of the patients had resumed sexual activity postoperatively. Obviously some kind of rehabilitation period is needed before resuming sexual activity. From ROC curves we found that the best cut-off value, for rehabilitation period as a predictor of regained EF, was 12 months or more (sensitivity $48 \%$, specificity $85 \%$ ) (Fig. 1). Further analyses were therefore made only in patients with postoperative follow-up of 12 months or more.

Table 1 shows preoperative sexual activity and preserved EF stratified according to pT-stage [4], Gleason score of the prostatectomy specimen, age and preoperative IIEF-5 score. As shown, the differentiation and local extend of the primary tumour were both of no significance to pre- and postoperative EF. Patient age at the time of surgery of 60 years or more was associated with an insignificant ( $p=0.6)$ higher prevalence of preoperative ED but a highly significant ( $<<0.01$ ) higher risk of ED postoperatively. Preoperative mild or moderate ED estimated from the IIEF-5 score was also associated with a highly significantly $(\mathrm{p}=0.01)$ higher risk of severe ED postoperatively.

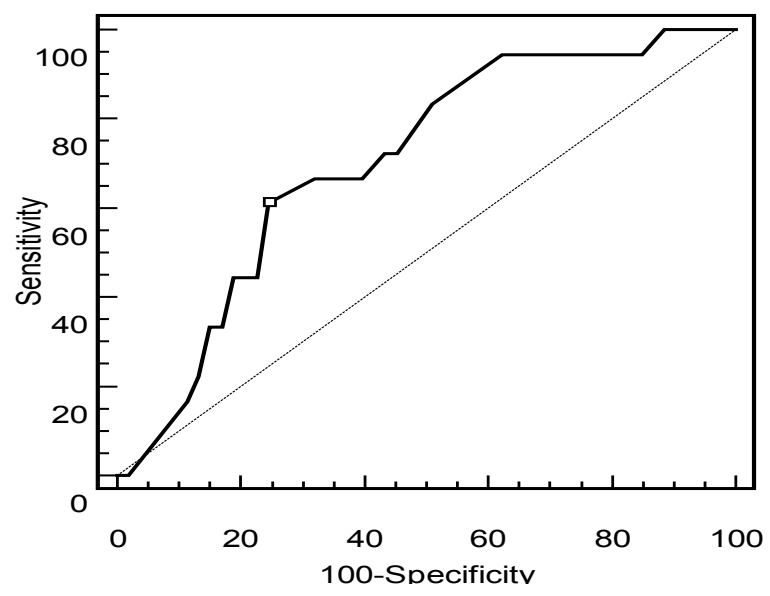

Figure 1. ROC Curve Displaying Postoperative Follow-Up Time as a Predictor af Recovered Erectile Function. Point of Highest Accuracy is Marked ( $\geq 12$ Months Follow-Up, Sensitivity 48 \%, Specificity 85 \%). 
Erectile Function Before and After Non-Nerve-Sparing Retropubic Radical Prostatectomy

Table 1. Results of erectile function questionnaires stratified according to histopathological and clinical features. Only patients with postoperative follow-up of 12 months or more are included in the table.

\begin{tabular}{|l|l|l|l|l|l|l|l|l|l|l|l|l|}
\hline & \multicolumn{3}{|l|}{ Pathological T-stage } & \multicolumn{2}{l|}{$\begin{array}{l}\text { Specimen } \\
\text { Gleason score }\end{array}$} & \multicolumn{3}{l|}{ Age (years) } & \multicolumn{2}{l|}{$\begin{array}{l}\text { Preoperative } \\
\text { IIEF-5 score* }\end{array}$} & Total \\
\hline & pT2a-b & pT2c & pT3 & $\leq 6$ & 7 & $\geq 8$ & $<60$ & $\geq 60$ & $\leq 21$ & $\geq 22$ & \\
\hline No. patients & 12 & 44 & 25 & 43 & 33 & 5 & 22 & 59 & 12 & 53 & 81 \\
\hline Preoperative sexual activity & & & & & & & & & & & \\
\hline - without medical aid (\%) & 67 & 77 & 76 & 72 & 79 & 80 & 82 & 73 & 83 & 96 & 75 \\
\hline - including medical aid (\%) & 75 & 84 & 76 & 77 & 85 & 80 & 86 & 78 & 100 & 100 & 80 \\
\hline Resumed sexual activity & & & & & & & & & & & \\
\hline - without medical aid (\%) & 0 & 15 & 26 & 13 & 19 & 25 & 22 & 14 & 0 & 20 & 16 \\
\hline - including medical aid (\%) & 44 & 43 & 47 & 48 & 36 & 75 & 74 & 32 & 8 & 53 & 45 \\
\hline $\begin{array}{l}\text { P-value - resumed sexual } \\
\text { activity including medical } \\
\text { aid }\end{array}$ & & & & & & & & & & & \\
\hline
\end{tabular}

* Only preoperative sexually active patients included in IIEF-5 score rows.

Of patients with 12 months follow-up or more, who were sexually active preoperatively, $16 \%$ had preserved EF without the need of medical aid. Including patients using PDE-5 inhibitors, a total of $20 \%$ had resumed sexual activity. When including use of prostaglandin analogues (intra-urethral or intracavernous), $45 \%$ of the preoperatively sexually active patients had resumed sexual activity.

IIEF-5 score of the patients with preserved EF was however significantly lower postoperatively compared to the preoperative score $(\mathrm{p}<0.01)$. Thus preoperative average score was $23.8 \pm 1.9 \mathrm{SD}$, while postoperative average score was $18.5 \pm 4.4 \mathrm{SD}$.

\section{Discussion}

In the available literature on EF following radical prostatectomy the definition of EF varies considerably. Some studies have used validated questionnaires whereas other uses terms like EF, ED, sexual function, potency and impotence without specifying further [5]. Postoperative follow-up of the patients also vary from 6, 12 or 24 months up to 60 months [6]. These facts make it difficult to compare surgical techniques and postoperative EF.

Several treatment options are available of localized prostate cancer: open surgery, laparoscopic or robotic surgery. All three modalities can be done non-nervesparing, unilaterally nerve-sparing or bilaterally nerve- sparing. Other treatments include cryotherapy, high intensity focused ultrasound (HIFU), brachytherapy, external beam radiotherapy and radiofrequency interstitial tumour ablation [7]. It is therefore challenging (but never the less necessary) to retrieve standardized, comparable knowledge of indications, contraindications, efficacy rate, complications and, as a part of complications, EF preservation for all available treatment modalities.

Studies on post-prostatectomy patients, not surprisingly, indicate that the nerve-sparing procedures (at least the bilateral procedure) are associated with a higher degree of EF preservation than the non-nerve-sparing procedure [8-11]. Thus Dubbelman et al. in a survey study found that $31-86 \%$ of the patients have preserved EF following bilateral nerve-sparing procedure while only 13-56 \% have preserved EF following a unilateral nerve-sparing procedure [12].

In NNS-RRP series postoperative EF frequencies of 0-17\% have been reported [9,10,12-15]. Our overall rate of preserved $\mathrm{EF}$ was $16 \%$ in patients without any medical aid. It is however important to bear in mind, that less than $60 \%$ of the patients had uncompromised EF preoperatively. If information about preoperative EF had not been available, the overall postoperative EF-rate would have been considerably lower. 
Another factor is the age of the patients. As shown by the present study, patient age at the time of surgery has great influence on postoperative EF. This is consistent with previously reported observations [12].

The presentstudy can be criticized for the retrospective design of the preoperative EF data. Especially the IIEF-5 questions will probably be defective to some degree. We do however believe that answers to the additional questions regarding sexual activity and medical aid are somewhat reliable.

The variable follow-up of the present study utilized to estimate the optimal length of postoperative followup regarding EF. In this way, 12 months which has been used by many studies has proved to be the best cut-off value.

Important is to accentuate the many patients benefiting from medical aid in the present study. Both
PDE-5 inhibitors and injection therapy may improve EF significantly.

Finally we find it important to emphasize that the radical prostatectomy is an intended curative treatment of a malignant disease where the primary goal always must be cancer control and not sexual activity. The oncological results from NNS-RRPs at our institution has been previously published [16]. These suggested acceptable local cancer control with a positive surgical margin in $12 \%$ of all patients and in less than $5 \%$ of patients with organ confined disease.

\section{ConClusions}

More than one third of patients subjected to radical prostatectomy may suffer from preoperative ED. Despite a non-nerve-sparing technique, EF is preserved in some patients following NNS-RRP. A relative large part of the patients may benefit from medical aid. High age and preoperative mild or moderate ED are all risk factors of total loss of EF postoperatively.

\section{APPENDIX 1}

Additional questions complementing the IIEF-5 pre- and postoperatively. Possible answers are given in italics. Preoperative:

1. Did you have any sexual activity within the last three months prior to surgery?

Yes or No

If no - why not? No erections/impotence

No partner

Lack of desire

Other - please state reason

2. Did you use any kind of aid in order to achieve or maintain erections?

Yes or No

If yes - which? Tablets - which?

Injections - which?

Other - please state which

Postoperative:

1. Have you had any sexual activity within the last three months?

Yes or No

If no - why not? No erections/impotence

No partner

Lack of desire

Other - please state reason

2. Do you use any kind of aid in order to achieve or maintain erections?

$\begin{array}{ll} & \text { Yes or No } \\ \text { If yes - which? } & \text { Tablets - which? } \\ \text { Injections - which? } \\ \text { Other - please state which }\end{array}$


Erectile Function Before and After Non-Nerve-Sparing Retropubic Radical Prostatectomy

\section{REFERENCES}

[1] Aus G, Abbou CC, Bolla M, Heidenreich A, Schmid $\mathrm{HP}$, Van $\mathrm{PH}$, et al. EAU guidelines on prostate cancer. Eur Urol 2005;48:546-51.

[2] Rosen RC, Cappelleri JC, Smith MD, Lipsky J, Pena BM. Development and evaluation of an abridged, 5 -item version of the International Index of Erectile Function (IIEF-5) as a diagnostic tool for erectile dysfunction. Int J Impot Res 1999;11:319-26.

[3] Metz CE. Basic principles of ROC analysis. Semin Nucl Med 1978;8:283-98.

[4] Sobin LH, Wittekind C. TNM Classification of Malignant Tumours. 6th ed. Hoboken, New Jersey: John Wiley \& Sons; 2002.

[5] Burnett AL, Aus G, Canby-Hagino ED, Cookson MS, D’Amico AV, Dmochowski RR, et al. Erectile function outcome reporting after clinically localized prostate cancer treatment. J Urol 2007;178:597-601.

[6] Penson DF, McLerran D, Feng Z, Li L, Albertsen PC, Gilliland FD, et al. 5-year urinary and sexual outcomes after radical prostatectomy: results from the prostate cancer outcomes study. J Urol 2005;173:1701-5.

[7] Beerlage HP. Alternative therapies for localized prostate cancer. Curr Urol Rep 2003;4:216-20.

[8] Kundu SD, Roehl KA, Eggener SE, Antenor JA, Han M, Catalona WJ. Potency, continence and complications in 3,477 consecutive radical retropubic prostatectomies. J Urol 2004;172:2227-31.
[9] Quinlan DM, Epstein JI, Carter BS, Walsh PC. Sexual function following radical prostatectomy: influence of preservation of neurovascular bundles. J Urol 1991;145:998-1002.

[10] Geary ES, Dendinger TE, Freiha FS, Stamey TA. Nerve sparing radical prostatectomy: a different view. J Urol 1995;154:145-9.

[11] Rabbani F, Stapleton AM, Kattan MW, Wheeler TM, Scardino PT. Factors predicting recovery of erections after radical prostatectomy. J Urol 2000;164:1929-34.

[12] Dubbelman YD, Dohle GR, Schroder FH. Sexual function before and after radical retropubic prostatectomy: A systematic review of prognostic indicators for a successful outcome. Eur Urol 2006;50:711-8.

[13] Davidson PJ, van den OD, Schroeder FH. Radical prostatectomy: prospective assessment of mortality and morbidity. Eur Urol 1996;29:168-73.

[14] Tsujimura A, Matsumiya K, Miyagawa Y, Takaha N, Nishimura K, Nonomura N, etal. Relation between erectile dysfunction and urinary incontinence after nerve-sparing and non-nerve-sparing radical prostatectomy. Urol Int 2004;73:31-5.

[15] McCammon KA, Kolm P, Main B, Schellhammer PF. Comparative quality-of-life analysis after radical prostatectomy or external beam radiation for localized prostate cancer. Urology 1999;54:509-16.

[16] Jonler M, Johansen J, Lund L, Pedersen KV, Graversen PH. [Radical prostatectomies for localized prostate cancer performed in center satellite collaboration--is it possible?]. Ugeskr Laeger 2007;169:1917-21.

Citation: Jørgen Bjerggaard Jensen, Jørgen K. Johansen. Erectile Function Before and After Non-NerveSparing Retropubic Radical Prostatectomy. Archives of Urology. 2018; 1(2): 5-9.

Copyright: (C) 2018 Jørgen Bjerggaard Jensen, Jørgen K. Johansen. This is an open access article distributed under the Creative Commons Attribution License, which permits unrestricted use, distribution, and reproduction in any medium, provided the original work is properly cited. 